\title{
Anatomia da Linguagem: Podemos Compreender Jogos de Linguagem a Partir de Redes Corticais?
}

\author{
Inês Hipólito \\ University International Postgraduate Award \\ School of Humanities and Social Inquiry \\ Faculty of Law, Humanities, and the Arts \\ University of Wollongong (Australia) \\ imh729@uowmail.edu.au
}

Há metáforas que são mais reais do que a gente que anda na rua.

Bernardo Soares

Resumo Há actualmente muito interesse na investigação dos substractos neuronais do processamento da metáfora. Tem vindo a ser sugerido que o hemisfério direito detém um papel essencial na compreensão da linguagem figurativa (não literal) e, em particular, nas metáforas. A linguagem figurativa integra-se na Pragmática, disciplina da linguística que se dedica ao estudo do uso da língua, por oposição ao estudo do sistema da língua. Continua, no entanto, aberto o debate sobre os aspetos específicos em que opera a semântica e aqueles em que domina a pragmática. Podem os estudos sobre correlatos neuronais clarificar questões sobre a representação semântica/pragmática? Analisaremos os avanços neurocientíficos sobre a linguagem implícita, para tentarmos perceber, na secção 2 , as técnicas científicas disponíveis e mais adequadas à fenomenologia do acto de compreender uma mensagem implícita, figurada ou implicada num determinado jogo de linguagem. Para tal, começaremos por rever os estudos em filosofia da linguagem, e acomodar o desenvolvimento da investigação em pragmática subjacente à metáfora, em particular nas Investigações Filosóficas de Wittgenstein. Finalmente, discuto a possibilidade de as capacidades interpretativas poderem ser socioculturalmente fundamentadas. Espera-se que esta metodologia de análise contribua para o esclarecimento do problema da fenomenologia da pragmática intersubjectiva, e para os seus futuros paradigmas experimentais.

Palavras-chave pragmática; linguagem figurativa; metáfora, jogos de linguagem, correlatos neurais; neuroimagem. 


\begin{abstract}
There is today much interest in research of neuronal substrata in metaphor processing. It has been suggested that the right hemisphere yields a key role in the comprehension of figurative language (non-literal) and, particularly, in metaphors. Figurative language is included in pragmatics, a branch of linguistics that researches the use of language, in opposition to the study of the system of language. There lingers, though, an open debate in respect to the identification of the specific aspects concerning semantics, as opposed to those dominated by pragmatics. Can studies from neuronal correlates clarify questions that relate to semantics/pragmatics representation? I shall analyze neuroscientific developments about implicit language to attempt to understand, in section 2 , scientific techniques available and more suitable to the phenomenology of the act of understanding an implicit, figurative or implicated message in a certain language game. To do so, I shall start by reviewing the studies in philosophy of language, and accommodate the development of the research in pragmatics underlying metaphor, particularly, in Philosophical Investigations by Wittgenstein. Finally, I discuss the possibility of interpretative capabilities being socioculturally grounded. I expect this methodological analysis to contribute to the enlightenment of the problem of phenomenology of intersubjective pragmatics, and to its future experimental paradigms.
\end{abstract}

Keywords: pragmatics, figurative language, metaphor, language games, neuronal correlates, neuroimage.

DOI $10.1515 / k j p s-2017-0004$

\title{
Introdução ${ }^{1}$
}

As últimas décadas, nos estudos acerca da compreensão do discurso, testemunharam avanços no que respeita a metodologias aplicadas e respectivo enquadramento teórico. Há, actualmente muito interesse na investigação dos substractos neurais do processamento da metáfora. Em particular, tem vindo a ser sugerido que o hemisfério direito detém um papel essencial na compreensão da linguagem figurativa (não literal) e, em particular, nas metáforas. Por outro lado, tem também vindo a ser proposto que as diferenças laterais entre linguagem literal ou metafórica podem dever-se a factores como a familiaridade ou dificuldade relativamente à figuração (Cardillo et al., 2016; Thompson et al, 2016; Schmidt e Seger, 2009; Bookheimer, 2002).

Podem apontar-se algumas razões possíveis para escassez de estudos de neuroimagem ao nível do processamento discursivo, algumas mantém-se ainda como problemas: (1) a investigação de neuroimagem em

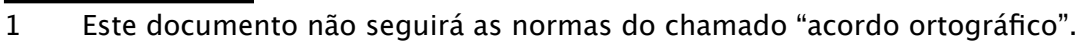


processamento da linguagem a qualquer nível é relativamente recente, (2) o processamento discursivo é um campo amplo sem uma tradicional preocupação acerca dos mecanismos neurais, (3) grande parte das questões-chave no processamento discursivo detém um caracter fenomenológico, portanto de difícil abordagem a partir da neuroimagem, (4) alguns dos frequentes paradigmas utilizados para investigar o processamento do discurso não são facilmente adaptáveis a um ambiente de scanner e (5) a carência de investigação neuropsicológica no processamento deficiente. Recentes avanços na tecnologia e conhecimento acerca das funções corticais vieram aliviar alguns dos constrangimentos descritos, abrindo novas e entusiasmantes possibilidades para a investigação dos substractos neurais subjacentes ao processamento neuronal da linguagem figurativa.

A linguagem figurativa integra-se na Pragmática, área da Linguística e da Filosofia da Linguagem que se dedica ao "estudo do uso da língua por oposição ao estudo do sistema da língua" (Reboul e Moeshler, 1998). Na linguística, é comummente aceite que a pragmática radica no princípio de que a interpretação de um enunciado não se pode fazer apenas baseada na informação linguística, uma vez que existe todo um conjunto de informações para-linguísticas, não linguísticas e contextuais que interferem e condicionam a produção e interpretação de cada enunciado. A análise do discurso é outra disciplina da linguística que se cruza frequentemente com a pragmática, ao necessitar de tomar em consideração parâmetros pragmáticos como a interação e o papel dos participantes, o contexto, o implícito, a dimensão jurídica do discurso (o discurso é sustentado por uma rede de direitos e obrigações que devem ser tidos em consideração), tais como a intersubjetividade, a modalidade, entre outros parâmetros.

A pragmática desenvolveu-se, na década de sessenta, a partir dos trabalhos dos filósofos da linguagem J. Austin e J. Searle sobre a teoria dos atos da linguagem e de H.P. Grice sobre o implícito e sobre a análise da conversação e das máximas conversacionais. A pragmática designa cada vez menos uma teoria particular, uma vez que converge a interseção de várias ciências humanas e de várias correntes de pensamento, de onde resultam as seguintes linhas de investigação: (1) semiótica inspirada na filosofia americana de C.S. Peirce; (2) a teoria dos atos de fala saída 
da investigação de J. Austin e continuada por J. Searle; (3) estudo das inferências percebidas pelos participantes de uma interação (H. P. Grice, D. Sperber e D. Wilson); (4) teoria da enunciação linguística desenvolvida pelos trabalhos de C. Bally, R. Jakobson, E. Benveniste, A. Culioli e a teoria polifónica de O. Ducrot; (5) Investigações sobre a argumentação na linguagem (O. Ducrot, C. Plantin; R. Amossy); (6) estudos sobre a interação verbal (C. Kerbrat-Orecchioni); finalmente, (7) teorias da comunicação desenvolvidas pela Escola de Palo Alto (G. Bateson, P. Watzlavick).

As principais tendências em pragmática repartem-se por três linhas de ação: a concepção de uma pragmática especificamente linguística (como defendido por O. Ducrot e J. C. Anscombre), a noção de processamento pragmático como decorrente do funcionamento do pensamento numa perspetiva cognitivista (cf. D. Sperber e D. Wilson) e uma interação equilibrada entre a pragmática e a linguística (cf. J. Moeshler e A. Reboul). Em Portugal os principais estudos em Pragmática têm sido principalmente desenvolvidos por Joaquim Fonseca, Fernanda Irene Fonseca, Maria Aldina Marques, Emília Pedro, Rui Ramos, entre outros. Continua, no entanto, em aberto o debate sobre os aspetos específicos em que domina análise semântica, por um lado, e aqueles em que domina a análise pragmática, por outro; sobretudo ao nível do estudo da referência nominal, da deixis, da força ilocutória de um enunciado, do implícito, da ironia, dos conectores, entre outros.

Iniciaremos este artigo com um enquadramento histórico da filosofia da linguagem e da psicolinguística quanto à evolução da compreensão pragmática do discurso. Seguidamente procederemos ao levantamento das técnicas imagiológicas que têm vindo a ser utilizadas para investigar esta capacidade linguística, avaliando resultados científicos. Sobretudo compreender, sob o ponto de vista científico, se será possível atribuir responsabilidades laterais à actividade cerebral. Por outro lado, pretende-se analisar validade científica das técnicas mais adequadas à compreensão fenomenológica do acto de compreender uma mensagem implícita, figurada ou implicada. Serão mais assertivas à condição fenomenológica da pragmática, as técnicas da psicologia, ou as técnicas especializas de imagiologia cerebral? 


\section{Perspectiva Histórica: a Psicologia da Linguagem}

É comummente aceite entre linguistas que a psicolinguística só começou efetivamente nos anos 50 . As suas raízes empíricas, no entanto, datam do final o século XVIII e é hoje uma área científica em expansão, para a qual contribuem outras investigações científicas como as da neurociência e as da filosofia da linguagem e da mente.

A psicolinguística possui quatro raízes históricas que emergiram no fim do século XIX. Nessa altura, a disciplina era convencionalmente chamada Psicologia da Linguagem. A primeira raiz foi linguística comparativa, a qual levantou a questão dos fundamentos psicológicos da linguagem. A segunda raiz foi o estudo da linguagem no cérebro, com Franz Gall como pioneiro e as descobertas de Broca $^{2}$ e Wernicke ${ }^{3}$ como grandes marcos. A terceira raiz funda-se no livro de Rousseau, Emile. A quarta raiz consistiu na abordagem experimental do processamento do discurso e da linguagem, o qual se originou no trabalho de Franciscus Donders. Wilhelm Wundt unificou estas quatro raízes no seu monumental Die Sprache of 1900. As quatro raízes prolongam-se para o século XX, mas em diferentes ramos de investigação (Levelt, 2014). As diferentes abordagens filosóficas parecem ter desencadeado problemas que levaram à defesa da necessidade de um caminho separado entre linguistas e psicológicos (Delbrück, 1901; Reber, 1987). Wundt, na Europa, desenvolveu os argumentos que conduziram ao behaviourismo nos Estados Unidos. Ironicamente, o behaviourismo veio a afectar o estudo da linguagem

2 A sua função é atuar como centro do discurso. Embora existam outras áreas do cérebro que também influenciam a fala (área de Wernicke e o córtex motor), a área de Broca é considerada o componente central. Situada no giro frontal inferior (áreas 44 e 45) do hemisfério cerebral dominante, logo acima do sulco lateral, é responsável pela função de emissão, execução, motricidade da fala. A Lesão desta área geralmente causa afasia motora, não-fluente ou agramatical. É importante notar que embora a área de Broca seja determinante para a linguagem (Zhang et al., 2017; Elmer, 2016), a lesão da área de Broca nem sempre causa afasia (Ardila et al., 2016), outras lesões também podem causar afasia (Dronkers, 1996), portanto várias objecções têm sido levantadas ao modelo clássico (Tremblay, 2016).

3 Área de Wernicke é uma região do cérebro humano responsável pelo conhecimento, interpretação e associação das informações, mais especificamente a compreensão da linguagem. Graves danos na área de Wernicke podem fazer com que uma pessoa que escuta perfeitamente e reconhece bem as palavras, seja incapaz de agrupar estas palavras para formar um pensamento coerente, caracterizando doença conhecida como Afasia de Wernicke, embora outras áreas também surjam associadas à afasia. 
quer dentro da psicologia, quer dentro da linguística ${ }^{4}$ (Altman, 2006). A obra de Bloomfield, Introduction to the Study of Language (1914), tinha, com efeito, uma orientação Wundteana: "aprendemos (...) que podemos conduzir o estudo da linguagem sem referência a qualquer doutrina psicológica"5. Na Psicologia, por outro lado, os behaviouristas estavam ansiosos por analisar o pensamento como um discurso subvocal, embora tivessem pouco a acrescentar acerca do discurso propriamente dito, ou qualquer outro aspecto da linguagem (Altman, 2006). Nos anos 50, Skinner publica o seu Verbal Behavior (1957). De acordo com os behavioristas, o propósito de Skinner seria bem diferente do de Chomsky. A Linguística de Bloomfield terá pouco contacto com a Psicologia behaviourista, tendo, no entanto impacto na emergência da Psicologia Cognitiva no século vinte.

A questão de saber como linguagem e pensamento se relacionam é bastante antiga e árdua e a hipótese Sapir-Whorf5 suscitou o entusiasmo de uma geração inteira de antropólogos, de psicólogos e de linguistas norte americanos; e, em menor escala, de europeus, nos anos 1940 e 50, antes de ser enfraquecida pela corrente cognitivista. A psicolinguística começa efectivamente na década de 50 com o seminário da Universidade de Cornel, levado a cabo para explorar as relações entre psicologia e linguística, e a publicação da Linguagem e Comunicação de George Miller (Levelt, 2014).

Mais tarde, Freud em The Psychopathology of Everyday Life (1975), introduziu a ideia de acto falhado (lapsos linguae) ou lapso freudiano 6 um erro na fala fruto de um desejo inconsciente. Outros estudos que surgem

$4 \quad$ De acordo com Altman, (2006), os trabalhos de Wundt influenciaram em grande medida a psicolinguística. De acordo com Blumenthal (1987), alguns linguistas foram em grande parte atraídos pelo trabalho empírico e filosófico do Laboratório de Leipzig de Wundt, que influenciou o próprio, assim como Mead, Saussure e Boas e os "jovens gramáticos" (Junggrammatiker).

5 As pessoas vivem segundo suas culturas em universos mentais muito distintos que estão exprimidos (e talvez determinados) pelas diferentes línguas que falam. Deste modo, também o estudo das estruturas de uma língua pode levar à elucidação de uma concepção de um mundo que a acompanhe.

6 Freud evidenciou que o ato falho era como sintoma, constituição de compromisso entre o intuito consciente da pessoa e o reprimido. Ato falho abrange também erros de leitura, audição ou dicção de palavras. São circunstâncias acidentais que não tem valor e não possuem consequência prática. Os atos falhos são compreendidos por muitas 
neste contexto são os do desenvolvimento infantil e de aquisição de linguagem que começam a ser tratados na obra de Rousseau, Émile (1762). Outros trabalhos, nesta área, mas de maior sofisticação linguística são os de Preyer (1881) e Stern \& Stern (1907). Outros estudos ainda são os dos movimentos oculares na leitura e que remontam também a este período (Cattell, 1886; Huey, 1908; Buswell, 1922; Tinker, 1932).

\subsection{Filosofia da Linguagem e Pragmática}

Frege, em Begriffsschrift (1879), elabora a sua escrita conceptual pretendendo depor a ambiguidade subjacente às línguas naturais. Em Uber Sinn und Bedeutung (1948 [1892]), introduz a distinção entre a referência de uma expressão e o sentido de uma expressão. Seguiu-se a teoria da denotação, de Bertrand Russell, On Denoting, publicado na revista Mind (1905), e Philosophy of Logical Atomism (1918), onde apresenta a Teoria das Descrições Definidas, a qual foi o grande instrumento analítico do Atomismo Lógico.

Wittgenstein afirmará que "na Psicologia há métodos empíricos e confusões conceptuais" (Wittgenstein, 1953). O Tractatus Logico-Philosophicus desempenha um marco da chamada viragem linguística, que colocou a linguagem natural e formal - o que engloba, naturalmente, a Lógica Simbólica - no cerne das discussões filosóficas. Com esta viragem, passa-se a analisar as condições para um discurso ter sentido ou conteúdo significativo. Desloca-se o tema da filosofia para um novo campo de apreciação organizada: a investigação sistemática da estrutura essencial da realidade ou mesmo da interação das faculdades subjectivas no acto do conhecimento e do tipo de acesso que temos ao mundo - o acento do desenvolvimento da filosofia moderna. Pode, portanto, afirmar-se que o Tractatus Logico-Philosophicus é um dos marcos filosóficos da premência da investigação sistemática da linguagem como propedêutica necessária para o entendimento - ou dissolução - de questões ontológicas ou epistemológicas. No que respeita à lógica, o Tractatus Logico-Philosophicus revolucionou a teoria da inferência dedutiva pela introdução de novos métodos e instrumentos que a transformaram numa área moderna de

pessoas como falta de atenção, cansaço, eventualidade, porém podem ser interpretados como manifestações reprimidas. 
intensa e proveitosa investigação científica, dissociando-a, finalmente, da gramática, da retórica e da psicologia.

John Austin (1911-1960), filósofo da linguagem comum, apresenta, nas obras Philosophical Papers (1961), Sense and Sensibilia (1962), How to Do Things With Words (1962), as noções de enunciados constativos versus enunciados performativos e descreve as condições de sucesso dos enunciados performativos. John Searle (n. 1932) sistematizou a teoria dos actos de fala, segundo a qual a unidade mínima de comunicação é o acto ilocutório e que este acto mostra a necessidade de recurso a conceitos mentais (Expression and Meaning: studies in the theory of speech acts, 1979). Outras obras importantes são: What is a speech act? (1965), Speech Acts: an essay in the philosophy of language (1969).

Além da teoria dos actos de fala, a abordagem de Paul Grice (19131988) da linguagem e da comunicação, é fundamental nos estudos pragmáticos. A intenção principal de Grice é explicar a significação (meaning) em termos de intenções. Studies in the Way of Words (1989), a obra publicada postumamente, que reúne o seu trabalho. As ideias destes autores (Austin, Searle, Grice) estão hoje por trás da pragmática. A publicação de Relevance Theory, por Sperber e Wilson (1986), ligou os estudos da linguagem e da comunicação aos emergentes estudos da cognição, através da Teoria da Relevância.

As várias considerações que medeiam o hiato entre significado da frase e significado do falante podem dividir-se em linguísticas, filosóficas e cognitivo-científicas. As linguísticas tendem a focar-se nos processos pragmáticos (Levinson, 2000; Horn, 1984, 2004). Os estudos filosóficos tendem a manter as normas conversacionais de Grice e a reconstruir a "Lógica Conversacional" que possibilita o significado implícito. As cognitivo-científicas da Teoria da Relevância estudam a natureza do sistema mental responsável pela interpretação dos enunciados (Sperber e Wilson, 2004). Estas teses são o substrato de muitas das investigações na psicologia evolucionista da arquitectura mental e de estudos clínicos da evolução comunicacional em crianças e em pessoas com debilitações comunicacionais.

Austin, Strawson e Wittgenstein (II) teorizam os significados da linguagem natural reagindo contra a "linguagem ideal" de Gottlob Frege e de 
Bertrand Russell. Nos últimos anos, os filósofos da linguagem comum e a tradição dos Actos de Fala, sob a influência do griceanismo reúnem-se à volta de duas propostas: semântica (frase é relativa ao contexto) e pragmática (contexto pertence a um Acto de Fala). O debate centra-se nas seguintes correntes, Minimalismo (Borg, 2007; Cappelen e Lepore, 2005); Parcialismo (Carston, 1998; Recanati, 2005); Indexicalismo (Stanley e Szabo, 2000; King e Stanley, 2005).

\subsubsection{Jogos de Linguagem}

Nas Investigações Filosóficas (1953), contrastando com o Tractatus Logico-Philosophicus, o grande argumento de Wittgenstein é o da recusa da Linguagem Privada. Wittgenstein abandona a ideia da linguagem como cálculo que envolve proposições, descrições, ou regras, abraçando a perspectiva da linguagem como 'jogo', um jogo de linguagem. Este é um conceito central na filosofia tardia de Wittgenstein, determinando um costume, uma forma social de interacção. Nesta medida, palavras e expressões tomam a sua significância quando usadas numa específica interação, ou, nos termos wittgensteineanos, numa forma de vida. Contrariamente ao que havia sido o pensamento positivista do circulo de Viena (e do próprio Wittgenstein do Tractatus), os jogos de linguagem não partilham nenhuma essência, cada um deles possui as suas características, regras e objectivos específicos. Exemplos de jogos de linguagem são: (1) dar ordens, e obedece-las, (2) descrever a aparência de um objecto, (3) construir um objecto a partir de uma descrição, (4) reportar um evento, (5) especular acerca de um evento, (6) formar uma hipótese experimental e apresentar resultados, (7) inventar uma história; e lê-la, (8) fazer de conta, (9) contar adivinhas, (10) fazer uma piada, (11) resolver um problema de aritmética, (12) traduzir de uma linguagem para outra, (13) pedir, gradecer, praguejar, cumprimentar, e rezar. Wittgenstein usou o termo jogos de linguagem em diferentes acepções, primeiro, actos de fala como pedir ou cumprimentar; segundo, como actividades, como fazer de conta, adivinhas; terceiro, linguagens primitivas como "bloco", "pilar" (PI §2); quarto, a linguagem como um todo, isto é, a linguagem e as acções nas quais se está envolvido (PI § 7).

Wittgenstein usa, assim, "jogos de linguagem" para enfatizar que (1) a linguagem é uma actividade que depende de uma determinada forma 
de vida, biológica, social e cultural; (regras arbitrárias e convencionais constituem jogos e gramáticas; (3) o significado das palavras é determinado pelas regras do seu uso (e não pelos objectos que representam, cf. Tractatus); (4) uma proposição ou uma jogada toma a significância do sistema ao qual pertence; (5) os jogadores estão envolvidos numa prática (linguística) social. No caso específico da capacidade de enunciação e compreensão de jogos metafóricos, trata-se de uma comunicação interpessoal que é uma masterização de social praxis. Uma praxis social porque, por não existir na natureza ou nas nossas vidas, é uma construção interpessoal, que só faz sentido na medida da experiência específica pessoal ou interpessoal. Wittgenstein compreende que a hierarquia da emersão consiste em palavras e expressões, elas próprias emersas em jogos de linguagem, os quais alternadamente, emergem na variedade das formas de linguagem, biológica, social ou cultural. Se a linguagem pode ser compreendida, portanto, à luz da emersão em formas de vida sociais e culturais, não redutíveis ao comportamento individual dos seus membros, mas como fenómeno emergente, a expressão metafórica é o seu expoente máximo. A metáfora claramente refere ao fenómeno interactivo da conversação, de acordo com a passagem "As palavras só têm significado no rio de pensamento e vida" (PI §174, 240, minha tradução). Qualquer investigação acerca da metáfora sem um estudo sério da componente social e cultural da fenomenologia da compreensão pragmática provar-se-á incompleta e inadequada.

\section{Anatomia da Linguagem}

\subsection{Imagem Especializada Para a Investigação do Processamento do Discurso Implícito e Figurado}

Num relativo curto espaço de tempo, a imagem cerebral tem contribuído para o estudo das estruturas corticais e sub-corticais na produção e compreensão da linguagem. Tendo em conta que facilita a medição da actividade cerebral relacionada com o processo da comunicação, fornece-nos a oportunidade de desenvolver uma compreensão do processamento da linguagem ao nível cortical. A associação de técnicas de neuro-imagem à investigação da linguagem contribui para explicar o mecanismo responsável por este actividade exclusivamente humana. 
Mais especificamente, a sua combinação com abordagens electrofisiológicas tem permitido estudar modelos de processamento de linguagem que captam não somente a distribuição espacial, do fenómeno cognitivo, como também a sua dimensão temporal, fornecendo, assim, novas pistas para a corrente de informação durante a comunicação.

A partir de 1980 os investigadores começaram a usar imagens cerebrais como uma forma singular de investigar o processo cognitivo. Nesta secção iremos começar por apresentar o papel da lateralização dos hemisférios no processamento linguístico, estudado através de técnicas de neuroimagem, para posteriormente evidenciar as situações metafóricas. Uma das primeiras investigações em neuroimagem foi a Tomografia por Emissão de Positrões (PET), num estudo sobre a compreensão metafórica conduzido por Bottini et al. (1994). As frases que continham metáforas aliciaram uma maior activação do hemisfério direito, sobretudo no giro frontal inferior direito talvez como o resultado de um processo de inferência, mais precisamente, a combinação entre conhecimento do mundo e conteúdo de uma frase soluciona a ambiguidade. Estas descobertas do envolvimento do hemisfério direito na compreensão da metáfora, combinados com os dados do campo visual e neurospicologia contribuíram para a hipótese de que o hemisfério direito não só está envolvido na compreensão da metáfora assim como de outras dimensões do discurso, como por exemplo a hipótese coarse-coding (Beeman et al., 1994; Brownell et al., 1986).

Uma das grandes vantagens da metodologia com $\mathrm{fMRI}^{7}$ é a janela temporal significativamente mais pequena que pode ser usada para medir a actividade cerebral comparativamente a PET. No processamento de linguagem, especialmente, o processo cognitivo que se pretende medir é muito curto, a fMRI permite uma imagem em várias janelas temporais consecutivas. Embora os primeiros estudos da compreensão do discurso através de fMRI utilizassem um design em bloco, tiraram partido de uma janela temporal mais rápida. O estudo em neuroimagem conduziu ao

$7 \quad$ fMRI mede a actividade neural através do aumento da corrente e volume sanguínea na área cortical onde está a decorrer um processo cognitivo. Consequentemente ocorre um aumento do oxigénio e o sinal da ressonância magnética através do ratio de hemoglobina desoxigenada e oxigenada. 
desenvolvimento de várias teorias do discurso tais como "coarse coding theory" do processamento do hemisfério direito (Beeman and Chiarello, 1998), o recrutamento dinâmico de redes em resposta a restrições textuais (Mason \& Just, 2004; Xu, Kemeny, Park, Frattali \& Braum, 2005), um sistema de Teoria da Mente responsável pela consciência (Gallagher $\&$ Frith, 2003). A activação cortical e estas novas teorias tem origens nas teorias tradicionais do discurso tais como o quadro de construção-integração (Construction-Integration framework) de Kintsch (1988), quadro de construção de estrutura (Structure Building framework, 1990), o modelo de ressonância de Myers e O'Brien (1998), a hipótese de saliência gradual (Graded Salience) de Giora (1997) e arquitectura de paisagem (Lanscape architecture) de van den Broek, entre outras.

Recentes desenvolvimentos de fMRI possibilitaram a medição da actividade cerebral durante a compreensão de frases individuais, isto é, isolar processos cognitivos individuais a frases individuais (cf. Mason e Just, 2004; Myers, Shinjo \& Duffy, 1987). O uso desta técnica permite identificar o intervalo de tempo da activação cortical que corresponde ao processamento crítico da frase.

Alguns estudos da imagem cerebral sobre o processamento do discurso foram desenvolvidos para determinar as bases neuronais da construção do modelo situacional. Um estudo de fMRI conduzido por St. George e colegas (1999), apresentou parágrafos sintaticamente bem estruturados, mas ininterpretáveis em virtude de nunca especificarem o seu referente no texto. Sem conhecimento do referente é difícil, se não impossível compreender a passagem "Typically, sucess requires that you start with your letf leg, and make sure that it is securelly in place. Then swing your body high into the air". Neste caso, se for fornecido um título, como por exemplo "ridding a horse ${ }^{9 "}$ toda a frase se torna compreensível.

Os estudos de fMRI revelam que o hemisfério esquerdo, como um todo, não sofre alterações de actividade quando o parágrafo é apresen-

8 "Geralmente, o sucesso requer que se comece com a perna esquerda e assegurar-se que esta está no lugar certo. Depois balouce o seu corpo no ar". (minha tradução).

9 Equitação. 
tado com o título, ou sem este; por outro lado, o hemisfério direito revela grande envolvimento durante a apresentação de um parágrafo sem o respectivo título. Mais especificamente, o médio esquerdo e o sulco superior temporal tornam-se mais activos durante o processamento dos parágrafos com título e, o médio direito e o sulco temporal superior tornam-se mais activos durante o processamento de parágrafos sem título. Estes resultados parecem evidenciar que o hemisfério direito está relacionado com o mapeamento de informação na representação textual. Por outro lado, os papéis do processamento dos dois hemisférios são, de facto, distinguíveis.

Tomitch, Just e Newman (2004) tentaram investigar o processamento diferencial dos hemisférios direito e esquerdo durante a integração textual, usando fMRI. O seu estudo consistiu em fazer variar a posição da frase tema no parágrafo, colocando-a quer na primeira posição (topic first) quer na terceira posição (topic last). Os resultados revelam efeitos diferenciais em ambos os hemisférios. O córtex temporal direito revela um forte envolvimento durante o processamento da frase tema, independentemente da sua localização no parágrafo. Em contraste, o córtex temporal esquerdo é sensível à localização da frase tema. A região temporal direita parece ser sensível à frase tema, mas não à sua localização, o que sugere que a região temporal direita é (1) sensível à potencial declaração presente no tópico e (2) desempenha um processamento adicional na frase tema potencial. Estes estudos conduzem-nos a conclusões importantes. O hemisfério direito parece responsável pelo uso de informação transmitindo ao hemisfério esquerdo para preencher o mapa de informação na representação textual construída pelo esquerdo e conectada com o conhecimento do mundo do participante. Este mapeamento de activação na região temporal direita foi também descoberto por Robertson et al. (2000) quer para artigos definidos quer indefinidos.

Maguire, Frith e Morris (1990) utilizaram passagens de Bransford e Johnson (1972) com ou sem títulos, também encontrando activação nas mesmas áreas quando há uma relação entre informação textual e o conhecimento a priori do sujeito. Estas operações parecem, portanto, centrais para a construção do modelo situacional, conectando o texto narrativo com o conhecimento acerca do mundo. As activações narrativas especificas (narrative-specific) também desencadeiam actividade 
na junção occipital-parietal-temporal, angular gyrus e sulco temporal superior. Uma visão preliminar indica que o gyrus angular desempenha um papel importante na tradução grafema para fonema.

Em suma, há uma quantidade significativa de investigação dos hemisférios na integração textual. Embora seja verdade que os dois hemisférios trabalham em conjunto para alcançar a função complexa que é a compreensão, parecem estar envolvidos em diferentes aspectos do processamento de discurso. Embora a identificação da ideia principal e a construção da representação textual seja separável do mapeamento da informação na estrutura do discurso, os dois hemisférios trabalham de modo interactivo para construir uma representação coerente do texto.

No que respeita especificamente à metáfora e ao discurso implícito, mais recentemente, Beaty e colegas (2017), usaram fMRI para explorar a interação das redes executivas de controlo focando a sua investigação nas interacções funcionais entre as regiões cerebrais durante a produção de metáforas. A análise da conectividade cerebral como um todo revelou uma rede distribuída associada à produção da metáfora, incluindo vários nódulos mais básicos (como precuneus, e o gyrus angular esquerdo), e redes de controlo executivo (sulcus direito intraparietal direito; IPS). Análises preliminares mostraram o aumento da conectividade entre estes centros de redes e conectividade temporal apontando para um mecanismo potencial entre os nódulos mais básicos e a rede de interacção executiva. Os resultados estendem-se a investigação recente sobre o papel cooperativo entre redes na cognição criativa, sugerindo que a produção da metáfora envolve redes semelhantes de dinâmica como outra forma de direcção a um objectivo e cognição auto gerada.

\subsection{Investigação Psicolinguista da Representação Interna do Dis- curso Implícito e Figurado}

Das três abordagens ao comportamento da linguagem, quer o behaviourismo, quer a teoria da informação foram rapidamente descartadas, sobretudo com a aparecimento da abordagem linguística.

O trabalho de Chomsky teve um enorme impacto quer na Linguística quer na Psicolinguística. As suas ideias foram cruciais no estudo empírico de aquisição de linguagem (Brown, 1973; Baker \& MacCarthy, 1981) e de fundamentos biológicos da linguagem (Lenneberg, 1967). Não obstante, 
Chomsky abandonou a ideia de que avanços no estudo experimental em psicologia pudessem ter impacto na teoria da linguística. Tendo a investigação teórica e empírica de Chomsky fundado um hiato nos anos sessenta que ainda não foi preenchido. Na verdade, nem a Semântica Generativa nem a Gramática Estrutural da Frase de 1970 e 1980 (que possuem obviamente um forte apelo psicológico), têm inspirado a investigação psicolinguística. O mesmo acontece com a linguística cognitiva (Altman, 2006). As considerações de Reber têm, no entanto, aberto o debate acerca da ligação entre a Linguística e a Psicologia.

Outra grande influência na investigação psicolinguista é o trabalho em Inteligência Artificial e em particular o trabalho de Minsky (1968) de processamento da informação semântica que culminou no trabalho de Winograd (1972). Outra grande influência foi Quillian (1968) com a noção de rede semântica para representar o significado. Desenvolvimentos frescos desde 1960 situam-se, justamente, na área do significado. Embora a rede semântica capte alguns factos interessantes acerca do significado, a Teoria Teoria é mais subtil (Murphy \& Medin, 1985). Recentemente têm vindo a surgir questões afins à polissemia e metonímia, questões colocadas também por Hilary Putnam (1975) na sua famosa discussão acerca de tipos naturais de termos.

É vulgarmente aceite que a compreensão do discurso requer que o leitor gere compreensões e extraia um significado que não está explícito no texto. Discurso implícito em frases metafóricas, na psicolinguística significa que, de acordo com a teoria de Lakoff e Johnson (1980), ao leitor ou interlocutor é pedido preencha o que está ausente ou ambíguo no texto, a teoria cognitiva da metáfora. Lakoff e Johnson estão preocupados em saber por que razão os conceitos do dia-a-dia são estruturados de uma forma e não de outra. Em particular, com os conceitos metafóricos, isto é, conceitos convencionais elaborados metaforicamente que podem tomar uma forma pública em expressões metafóricas. Há um conjunto de conceitos metafóricos, à volta dos quais o mundo se organiza.

Um dos trabalhos mais influentes foi o modelo situacional desenvolvido por van Dijk e Kintsch (1983). O modelo situacional surge do processamento linguístico de texto propriamente dito (acesso lexical processamento sintático, construção baseada em estruturas-micro) e uma interacção com processos cognitivos não linguísticos. O modelo 
situacional é o resultado desta interacção criada para conectar exigências adicionais (como por exemplo, a capacidade de mudar de pontos de vista e analise de sequência de eventos), memória de trabalho (reter referências de longo termo e anafóricas) e a contribuição da imagem visual e conhecimento emocional.

Frequentemente as ligações entre os eventos numa história não estão explicitamente ditos e o leitor tem de conectá-los gerando inferências e integrando a nova informação na anterior. As inferências prestam-se a preencher o que está em falta na informação, resolver discrepâncias nas inferências, que podem ser de natureza predicativa, elaborativa ou causal ${ }^{10}$. Uma inferência bem sucedida geralmente resulta da integração dessa inferência numa representação interna do texto ${ }^{11}$. Como vimos anteriormente, têm havido alguns estudos de ressonância magnética funcional (fMRI) no processamento da inferência. Uma das questões hot topic tem que ver com as inferências baseadas no raciocínio lógico que parecem ser processadas do mesmo modo que as inferências. Caplan e Dapretto (2001), nos seus estudos em fMRI, compararam inferências lógicas com inferências baseadas em texto. Há dois tipos de pares, tal como os seguintes:

"baseado no texto

'Acreditas em anjos?'

'Sim, tenho o meu anjo especial.'

Baseado na lógica

'Gostas de te divertir?

Sim, porque me faz feliz.'”

Enquanto a condição lógica produziu maior activação nas áreas esquerdas de linguagem, as condições baseadas em texto, revelaram mais activação no hemisfério direito. Este estudo é significante porque sugere que, ao nível neural, e consequentemente ao nível de processamento, há diferenças significantes entre inferências lógicas vs. textuais. Por outro lado, os estudos parecem convergir com as descobertas neu-

10 Para mais detalhe sobre tipos de inferência, ver Singer, 1994; van den Broek, 1994.

11 Cf. modelo de Construção-integração (Cl) de compreensão de texto (Kintsh, 1988). 
ro-psicológicas que mostram que o hemisfério direito está intimamente envolvido no processamento relacionado com texto.

Mason e Just (2004) desenharam um estudo que teve como objetivo examinar as áreas corticais envolvidas nas inferências causais durante a leitura. Os participantes liam pares de frases que variavam em relação causal, como por exemplo "O irmão mais velho do Joey bateu-lhe vezes sem conta"; "A mãe maluca do Joey ficou outra vez furiosa com ele"; "O Joey foi a brincar para casa do vizinho". Este estudo descobriu três áreas foco na actividade cortical. No hemisfério esquerdo das áreas de linguagem, o volume de activação não varia em proporcionalidade com as condições de relação. Por outro lado, o volume de activação nos córtices bilaterais pré-frontais dorsolaterais, mostra um aumento em função do enfraquecimento gradual de relação causal. Finalmente, o volume de activação foi observado no hemisfério direito homologo às áreas de linguagem: a activação é consistente com os padrões de reconhecimento. Duas áreas corticais diferentes parecem estar subjacentes à geração e integração de inferências durante a leitura. A primeira rede, que consiste no córtex pré-frontal dorsolateral direito e esquerdo está mais envolvida na geração de inferências. A segunda, que consiste no gyrus inferior direito, superior direito e giro temporal médio, e no lobo inferior parietal direito está mais envolvida na integração de possíveis inferências.

A pesquisa só agora começa a desenhar a rede cortical associada ao mapeamento de inferências na leitura. As evidências sugerem que o hemisfério direito desempenha um papel-chave no processo. Neste contexto, surgem teorias plausíveis para compreender o papel do hemisfério direito. Reichle e Mason (2005), com base nos trabalhos por Just e colegas, propuseram que uma capacidade limitada seja ultrapassada através de processos de inferência. Isto leva à ideia de que a transformação é passada para o hemisfério direito, contrastando com o que foi proposto por Mason e colegas, que o hemisfério direito é utilizado durante a integração de um inferência e inferências que são gerados utilizando o córtex pré-frontal dorso lateral. 


\section{Discussão e Conclusão}

O processamento do discurso é uma tarefa cognitiva de alto nível. A possibilidade da investigação neuroimagiológica examinar em larga escala a rede cortical de especialização diferenciada nas regiões cerebrais enquanto se manipula o carregamento de vários aspectos da cognição torna esta metodologia ideal para o avanço na nossa compreensão do processamento do discurso. A natureza diversa da investigação revista neste trabalho demonstra que estamos tão-somente no início da viragem neuroimagiológica no nosso entendimento da compreensão do discurso. A neuroimagem permite não só abordar de modo actualizado teorias antigas, como também fornecer dados que podem sugerir novas teorias de base para a compreensão do discurso. A possibilidade de estudos com imagem especializada fMRI no exame de diferentes áreas corticais permite especular como várias teorias do discurso podem ser integradas num todo. Grande parte da investigação por neuroimagem desenvolvida até hoje, pode servir como prova para vários processos de discurso propostos, e assim suportar ou falsificar determinadas teorias.

Para concluir, é bastante evidente que a neuroimagem oferece uma possibilidade de investigar o processamento do discurso de um modo nunca antes feito. Do ponto de vista da investigação em neuroimagem, parece haver lateralização na compreensão de frases individuais (Mason and Just, 2004; Keenan, Baillet and Brown, 1984), no processamento do discurso (St. George e colegas, 1999), processamento diferencial dos hemisférios direito e esquerdo durante a integração textual (Tomitch, Just e Newman, 2004), na relação entre informação textual e o conhecimento a priori do sujeito (Maguire, Frith e Morris, 1990). Os estudos em psicolinguística seguem em grande medida o modelo cognitivo da metáfora, destacando-se o modelo situacional (Dijk e Kintsch, 1983), a comparação entre inferências lógicas e inferências baseadas em texto (Caplan e Dapretto, 2001); inferências causais durante a leitura (Mason e Just, 2004).

Resta-nos concluir, no entanto, que são poucos os estudos que se direcionam estritamente para o estudo da metáfora. Apresentámos e analisámos situações linguísticas que se se situam nas fronteiras com as situações metafóricas e implícitas. Estes estudos decerto contribuem para 
a compreensão anatómica do processamento da metáfora, e expectamos que com o desenvolvimento de novas técnicas de maior precisão temporal e espacial, novas fronteiras neurocientíficas se tracem. No entanto, devemos ainda perguntar se a compreensão neuronal e anatómica é satisfatória para a compreensão do fenómeno metafórico. Tal como tivemos oportunidade de teorizar na primeira secção, a dimensão de 'jogo', como uma comunicação interpessoal que é uma masterização de praxis biológica, social e cultural, e que parece impossível reduzir ao comportamento individual dos seus membros, fica lamentavelmente aquém das lentes de investigação empíricas. O fenómeno da metáfora como emergente da interacção da conversação, pode abrir novas portas de debate epistemológico e ferramentas empíricas. A grande vantagem desta abordagem teórica, parece-me, é a da possibilidade de examinar a rede como um todo, revelando novos aspectos do processamento do discurso. Importa relembrar como o estudo apresentado por Beaty e colegas (2017), demonstra o aumento da conectividade entre centros de redes mais básicos e conectividade temporal apontando para um mecanismo potencial entre os nódulos mais básicos e a rede de interacção executiva. Este estudo parece-me relevante porque os seus resultados parecem indicar a direcção do papel cooperativo entre redes na cognição criativa, sugerindo que a produção da metáfora envolve redes semelhantes de dinâmica como outra forma de direcção a um objectivo e cognição auto gerada.

Uma possível explicação para estes resultados poderá instanciar-se no facto de que a metáfora, por não ter existência no mundo ou nas nossas vidas, ser fruto de uma criação resultante da e na prática social e/ou cultural. Portanto, de uma construção interpessoal, que só faz sentido no jogo da experiência específica pessoal ou interpessoal e que, neurologicamente, podemos colocar em hipótese, se pode traduzir em largas redes funcionais dinâmicas, isto é, inter-regionais e entre redes mais básicas e outras executivas que cooperam para gerar um objectivo cognitivo específico que implica a criatividade.

Esta perspetiva da linguagem, particularmente da metáfora, como um jogo de interacção imediata, que constrói do improviso da sua autonomia e significação, deve ser tomada em conta no sentido de implementar um novo paradigma de estudo experimental e cujo objectivo, 
além de descobrir os correlatos neuronais, seja também o de evidenciar precisamente a dimensão fenomenógica e intersubjectiva da metáfora, que parece ainda aquém dos objectivos empíricos. O trabalho de Wittgenstein e de outros filósofos certamente contribuiu para a consciência dos linguistas acerca do que a filosofia contemporânea pode oferecer à teoria da linguagem, particularmente no que respeita à pragmática. Vários fenomenólogos europeus têm vindo a trabalhar na descrição da experiencia básica da linguagem, defendendo que a linguagem não é simplesmente uma ferramenta usada para partilhar experiência, mas que é intrínseca ao desenvolvimento e às possibilidades da experiência linguística (Albertazzi, 2000), investigando o primeiro nível da experiência da linguagem, seguindo a psicologia de Gestalt e da espontaneidade da experiência linguística; cuja interpretação é directamente dada na experiência, e não adicionada ou inferida dela. Outros filósofos têm realçado a importância da narrativa (Gallagher, 2016, Hutto, 2012; Gallagher and Hutto, 2008), e a possibilidade de que as nossas capacidades interpretativas podem ser socioculturalmente fundamentadas (a hipótese da prática narrativa), isto é, através dos encontros directos com estórias acerca das pessoas que agem por razões, tendo estas as características essenciais para potenciar uma compreensão explícita das formas e normas da intersubjectividade. Novos mecanismos teóricos e novas ferramentas empíricas parecem potenciar o auscultar da realidade fenomenológica subjacente ao jogo de linguagem.

\section{Agradecimentos}

A autora agradece as importantes sugestões e comentários dos revisores anónimos que tornaram este artigo mais claro e assertivo.

\section{Referências}

Albertazzi, L. (Ed.). (2000). Meaning and cognition: A multidisciplinary approach. John Benjamins Publishing.

Altmann, G.T.M. (2006). History of Psycholinguistics. in K. Brown (ed). The Encyclopedia of Language and Linguistics (2nd edition). Elsevier. 
Austin, J.L. (1979). Philosophical papers. Oxford: Oxford University Press.

--- (1962). Sense and Sensibilia. (Warnock, ed.), Oxford: Oxford University Press.

Beaty, R.E., Silvia, P.J., \& Benedek, M. (2017). Brain networks underlying novel metaphor production. Brain and Cognition, 111, 163-170.

Baker, C.L., \& McCarthy, J.J. (Eds). (1981). The logical problem of Ianguage acquisition. Cambridge, MA: MIT Press.

Beeman, M.J., \& Chiarello, C. (1998). Complementary right-and left-hemisphere language comprehension. Current Directions in Psychological Science, 7(1), 2-8.

Borg, E. (2007). Minimalism versus contextualism in semantics (pp. 339-359). Oxford: Oxford University Press.

Beeman, M., Friedman, R.B., Grafman, J., Perez, E., Diamond, S., \& Lindsay, M.B. (1994). Summation priming and coarse semantic coding in the right hemisphere. Journal of Cognitive Neuroscience, 6, 26-45.

Blumenthal, A.L. (1987). The emergence of psycholinguistics. Synthese, 72, 313-323.

Bloomfield, L. (1914). Introduction to the study of language. New York: Henry Holt and Company.

Bottini, G., Corcoran, R., Sterzi, R., Paulesu, E., Schenone, P., Scarpa, P., Frackowiak, R.S.J., \& Frith, C.D. (1994). The role of the right hemisphere in the interpretation of figurative aspects of language: A positron emission tomography activation study. Brain, 117, 1241-1253.

Brown, R. (1973). A first language: The early stages. Cambridge, MA: Harvard University Press.

Brownell, H.H., Potter, H.H., Bihrle, A.M., \& Gardner, H. (1986). Inference deficits in right brain-damaged patients. Brain and Language, 29, 310-321.

Buswell, G.T. (1922). Fundamental reading habits: A study of their development. Chicago, IL: University of Chicago Press. 
Bransford, J.D., \& Johnson, M.K. (1972). Contextual prerequisites for understanding: Some investigations of comprehension and recall. Journal of Verbal Learning and Verbal Behavior, 11, 717-726.

Cardillo, E.R., Watson, C., \& Chatterjee, A. (2016). Stimulus needs are a moving target: 240 additional matched literal and metaphorical sentences for testing neural hypotheses about metaphor. Behavior research methods, 1-13.

Catania, A.C. (1998). The taxonomy of verbal behavior. In: K.A. Lattal, $\&$ M. Perone (Eds), Handbook of research methods in human operant behavior (pp. 405-433). New York: Plenum.

Caplan, R., \& Dapretto, M. (2001). Making sense during conversation: An fMRI study. NeuroReport, 12, 3625-3632.

Cappelen, H., \& LePore, E. (2005). Quotation, The Stanford Encyclopedia of Philosophy (Spring 2012 Edition), Edward N. Zalta (ed.), URL $=\langle$ https://plato.stanford.edu/archives/spr2012/entries/quotation $/>$.

Cattell, J. (1886). The time it takes to see and name objects. Mind, 11, 63-65.

Delbrück, B. (1901). Grundfragen der Sprachforschung; mit rücksicht auf W. Wundt's Sprachpsychologie. Strassburg: Trabner.

Dronkers, N.F. (1996). A new brain region for coordinating speech articulation. Nature, 384 (6605), 159.

Elmer, S. (2016). Broca Pars Triangularis Constitutes a "Hub" of the Language-Control Network during Simultaneous Language Translation. Frontiers in Human Neuroscience, 10.

Eviatar, Z., \& Just., M.A. (2006). Brain correlates of discourse processing: An fMRI investigation of irony and conventional metaphor comprehension. Neurpsychologia, 44, 2348-2359.

Ferstl, E.C., \& Von Cramon, D.Y. (2001). The role of coherence and cohesion in text comprehension: An event-related fMRI study. Cognitive Brain Research, 11, 325-340.

Frege, G. (1879). Concept script, a formal language of pure thought modelled upon that of arithmetic. In: J. Van Heijenoort (ed.) From Frege to Gödel: A Source Book in Mathematical Logic: 1879-1931. Cambridge (Mass.): Harvard University Press, 1967. 
Frege, G. (1948 [1892]), Sense and reference. The philosophical review, 57(3), 209-230.

Freud, S. (1975). The psychopathology of everyday life (Trans. A. Tyson). Harmondsworth, UK:Penguin (originally published 1901).

Gallagher, S. (2016). On the limits of finding human identity in the brain. Modern Believing, 57(2), 121-130.

Gallagher, H.L., \& Frith, C.D. (2003). Functional imaging of 'theory of mind'. Trends in Cognitive Neuroscience, 7, 77-83.

Gallagher, S., \& Hutto, D. (2008). Understanding others through primary interaction and narrative practice. The shared mind: Perspectives on intersubjectivity, 12, 17-38.

Gernsbacher, M.A. (1990) Language comprehension as structure building. Hillsdale, NJ: Lawrence Erlbaum Associates.

Giora, R. (1997). Understanding figurative and literal language: The graded salience hypothesis. Cognitive Linguistics, 7, 183-206.

Grice, H.P. (1991). Studies in the Way of Words. Harvard University Press.

Huey, E.B. (1908). The psychology and pedagogy of reading. New York: Macmillan.

Hutto, D.D. (2012). Folk psychological narratives: The sociocultural basis of understanding reasons. MIT Press.

King, J., \& Stanley, J. (2005). Semantics, pragmatics, and the role of semantic content. Semantics versus pragmatics, 111-164.

Kintsch, W. (1988). The role of knowledge in discourse comprehension: A construction-integration model. Psychological Review, 95, 163-182.

Lakoff, G., \& Johnson, M. (1980). The metaphorical structure of the human conceptual system. Cognitive science, 4(2), 195-208.

Lenneberg, E.H. (1967). Biological foundations of language. New York: Wiley.

Levelt, W. (2014). A history of psycholinguistics: The pre-Chomskyan era. Oxford University Press. 
Maguire, E.A., Frith, C.D., \& Morris, R.G.M. (1999). The functional neuroanatomy of comprehension and memory: The importance of prior knowledge. Brain, 122, 1839-1850.

Mason, R.A., \& Just, M.A. (2004). How the brain processes causal inferences in text: A theoretical account of generation and integration component processes utilizing both cerebral hemispheres. Psychological Science, 15, 1-7.

--- (2006). Neuroimaging contributions to the understanding of discourse processes. Handbook of psycholinguistics, 799.

Minsky, M. (Ed.) (1968). Semantic information processing. Cambridge, MA: MIT.

Murphy, G.L., \& Medin, D.L. (1985). The role of theories in conceptual coherence. Psychological review, 92(3), 289.

Quillian, M.R. (1968). Semantic memory. In: M. Minksy (Ed.), Semantic information processing. Cambridge, MA; MIT Press, 227-270.

Myers, J.L., \& O'Brien, E.J. (1998). Accessing the discourse representation during reading. Discourse Processes, 26, 131-157.

Myers, J.L., Shinjo, M., \& Duffy, S.A. (1987). Degree of causal relatedness and memory. Journal of Memory and Language, 26(4), 453-465.

Reber, A.S. (1987). The rise and (surprisingly rapid) fall of psycholinguistics. Synthese, 72: 325-339.

Recanati, F. (2005). Literalism and contextualism: Some varieties. In: G. Preyer and G. Peter (eds.), Contextualism in philosophy: Knowledge, meaning, and truth. Oxford: Oxford University Press: 171-196.

Reboul A. \& Moeschler J. (1998), Pragmatique du discours. De l'interprétation de l'énoncé à l'interprétation du discours, Paris, Armand Colin (U linguistique).

Reichle, E.D. \& Mason, R.A. (2006). The neural signatures of causal inferences: A preliminary computational account of brain-imaging and behavioral data. In: F. Schmalhofer, \& C.A. Perfetti (Eds), Higher level language processes in the brain: Inference and comprehension processes. Mahwah, NJ: Erlbaum.

Robertson, D.A., Gernsbacher, M.A., Guidotti, S.J., Robertson, R.R.W., Irwin,W., Mock, B.J., \& Campana, M.E. (2000). Functional neuroanatomy 
of the cognitive process of mapping during discourse comprehension. Psychological Science, 11, 255-260.

Russell, B. (2009). The philosophy of logical atomism. Routledge.

Russell, B. (2005). On denoting. Mind, 114(456), 873-887.

Searle, J.R. (1985). Expression and meaning: Studies in the theory of speech acts. Cambridge University Press.

Searle, J.R. (1965). What is a Speech Act?. England: Penguin books.

Searle, J.R. (1969). Speech acts: An essay in the philosophy of language (Vol. 626). Cambridge university press.

Schmidt, G.L., \& Seger, C.A. (2009). Neural correlates of metaphor processing: the roles of figurativeness, familiarity and difficulty. Brain and cognition, $71(3), 375-386$.

Skinner, B.F. (1983). Verbal Behavior, 1957. New York: Appleton-Century-Crofts.

Sperber, D., Wilson, D., (1986). Relevance: Communication and cognition (Vol. 142). Cambridge, MA: Harvard University Press.

Stanley, J., \& Gendler Szabó, Z. (2000). On quantifier domain restriction. Mind \& Language, 15(2-3), 219-261.

St George, M., Kutas, M., Martinez, A., \& Sereno, M.I. (1999). Semantic integration in reading: engagement of the right hemisphere during discourse processing. Brain, 122(7), 1317-1325.

Tinker, M.A. (1936). Reliability and validity of eye-movement measures of reading. Journal of Experimental Psychology, 19, 732-746.

Tomitch, L.M.B., Just, M.A., \& Newman, S.D. (2004). Main idea identification: a functional imaging study of a complex language comprehension process. In C. Rodrigues, \& L.M.B. Tomitch (Eds.), Linguagem e o Cérebro Humano: Contribuições multidisciplinares (pp. 167-175). ATMED editora, Portoalegre.

Tremblay, P., \& Dick, A.S. (2016). Broca and Wernicke are dead, or moving past the classic model of language neurobiology. Brain and Language, 162, 60-71. 
Thompson, H.E., Henshall, L., \& Jefferies, E. (2016). The role of the right hemisphere in semantic control: A case-series comparison of right and left hemisphere stroke. Neuropsychologia, 85, 44-61.

Van Dijk, T., Kintsch, T., (1983). Strategies of Discourse Comprehension. New York: Academic Press.

Xu, J., Kemeny, S., Park, G., Frattali, C., \& Braun, A. (2005). Language in context: Emergent features of word, sentence, and narrative comprehension. Neurolmage, 25, 1002-1015.

Winograd, T. (1972). Understanding natural language. Cognitive Psychology, 3, 1-191.

Wittgenstein, L. (1921). Tractatus logico-philosophicus (Trans, D.F. Pears \& B.F. McGuinness, 1961). London: Routledge \& Kegan Paul.

Wittgenstein, L. (1999). Philosophical investigations, trans. GEM Anscombe. New York: The Macmillan Company.

Zhang, Y., Fan, L., Caspers, S., Heim, S., Song, M., Liu, C. et al. (2017). Cross-cultural consistency and diversity in intrinsic functional organization of Broca's Region. Neurolmage, 150, 177-190. 